\title{
Rekonstruksi Laporan Zakat, Infak, Shadaqah pada Lembaga Masjid Berdasarkan PSAK 109
}

\author{
Siti Khorimah ${ }^{1 *}$, Yulinartati ${ }^{2}$, Astrid Maharani ${ }^{3}$ \\ 1,2,3 Program Studi Akuntansi Fakultas Ekonomi dan Bisnis Universitas Muhammadiyah Jember
}

\author{
A R T I C L E I N F O \\ Article history: \\ Received 19 August 2019 \\ Received in revised form \\ 16 September 2019 \\ Accepted 15 October 2019 \\ Available online 30 \\ November 2019 \\ Kata Kunci: \\ Rekonstruksi, PSAK 109, \\ Masjid \\ Keywords: \\ Reconstruction, PSAK 109, \\ Mosque
}

\begin{abstract}
A B S T R A K
Penelitian ini bertujuan untuk mengetahui laporan keuangan yang disiapkan oleh lembaga Masjid Baitur Roja 'Jember kemudian membandingkannya dengan pernyataan Standar Akuntansi Keuangan Nomor 109 tentang akuntansi zakat, infaq, shadaqah dan merekonstruksi menjadi laporan keuangan berdasarkan PSAK 109. Aplikasi ini sangat dibutuhkan oleh lembaga-lembaga masjid karena selain menjadi pedoman serta pertanggungjawaban kepada pihak terkait seperti donor atau muzakki. Penelitian ini menggunakan metode deskriptif kualitatif dan data donatur atau muzakki. Penelitian ini menggunakan metode deskriptif kualitatif dan metode pengumpulan data yang digunakan dengan cara wawancara, observasi dan dokumentasi. Hasil penelitian ini menunjukkan bahwa penyusunan laporan keuangan lembaga Masjid Baitur Roja 'Jember tidak sesuai dengan PSAK 109 karena laporan keuangan yang disusun masih sederhana, yaitu pencatatan dalam bentuk penerimaan dan pengeluaran dana masjid. Setelah direkonstruksi, dalam penerapan laporan keuangan dihasilkan sesuai dengan PSAK No.109 yang terdiri dari laporan posisi keuangan, laporan perubahan dana, perubahan aset dalam manajemen, laporan arus kas, dan catatan atas laporan keuangan.
\end{abstract}

\section{A B S T R A C T}

This study aims to find out the financial statements prepared by the Baitur Roja' Jember Mosque institution then compared with the statement of Financial Accountung Standards Number 109 concerning accounting for zakat, infaq, shadaqah and reconstructing it into financial statements based on PSAK 109. This application is urgently needed by mosque institutions because in addition to being a guideline as well as accountability to the parties concerned such as donors or muzakki. This study uses descriptive qualitative method and data donatur or muzakki. This study uses descriptive qualitative methods and data collection methods used by means of interviews, observation and documentation. The result of this study indicate that the preparation of the financial statements of the Baitur Roja' Jember Mosque institution is not in accordance with PSAK 109 because the financial statement prepared are still simple, namely recording in the form of receipt and expenditure of mosque funds. After being reconstructed, in the application of financial statements is produced in accordance with PSAK No.109 which consists of statements of financial position, reports of changer in funds, changes in assets under management, cash flow statements and notes to financial statements.

\footnotetext{
* Corresponding author.

E-mail addresses: Khorimahsiti@yahoo.co.id (Siti Khorimah)
} 


\section{Pendahuluan}

Indonesia merupakan salah satu negara yang berpenduduk muslim terbesar di dunia. Lebih dari delapan puluh lima persen penduduk di Indonesia beragama Islam sehingga potensi zakat di Indonesia sangat besar. Ketua Badan Amil Zakat, Bambang Sudibyo mengatakan bahwa potensi zakat yang dimiliki umat islam cukup besar. Pada tahun 2016, zakat yang diperoleh sekitar Rp 217 triliun dan terakhir pada tahun 2017 mencapai Rp 6,22 triliun atau meningkat 30 persen dibandingkan dengan tahun sebelumnya (Republika,21/09/2018). Hal tersebut dapat menimbulkan berdirinya suatu organisasi yang berbasis islam, salah satu organisasi tersebut adalah organisasi yang mengelola zakat dan infaq/shadaqah.

Zakat merupakan salah satu dari rukun islam yang wajib ditunaikan atas harta kekayaan individu yang ketentuannya telah diatur melalui aturan tertentu yang berpedoman kepada Al Qur'an dan As Sunnah. Masjid merupakan sarana peribadatan dan kegiatan umat Islam yang secara tidak langsung memerlukan ilmu dan praktik akuntansi dalam memunculkan pelaporan keuangan yang efektif. Hal ini dikarenakan masjid juga memerlukan informasi yang menunjang kegiatan peribadatan, kegiatan kegamaan serta aktivitas perawatan dan pemeliharaan masjid. Pendanaan masjid berasal dari masyarakat yang sebagian besar berasal dari sumbangan publik yang biasanya disebut dengan zakat dan infaq/shadaqah dimana, sebagian besar transaksi yang terjadi berdasarkan dengan ketentuan syariah sesuai dengan ajaran islam. (Pratama, 2017).

Laporan keuangan masjid merupakan hal yang sangat penting untuk diteliti dan dievaluasi khususnya dalam prinsip transparansi dan akuntabilitas pada masyarakat, termasuk publikasi dalam pertanggung jawaban laporan keuangan. Adanya informasi keuangan dapat digunakan sebagai dasar pertimbangan dalam proses pengambilan suatu keputusan. Di dalam menyusun laporan keuangan masjid, Ikatan Akuntan Indonesia (IAI) memiliki peranan yang penting sebagai pembentuk Standar Akuntansi Keuangan secara tertulis dengan menerbitkan PSAK Nomor 109 yang mengatur tentang akuntansi zakat, infaq dan shadaqah merupakan sumber dana keuangan yang terdiri dari laporan posisi keuangan, laporan perubahan dana, perubahan aset kelolaan, laporan arus kas dan catatan atas laporan keuangan.

Berdasarkan latar belakang penulisan maka rumusan masalah yang hendak diteliti dituangkan dalam bentuk pertanyaan yaitu bagaimanakah kesesuaian penyusunan akuntansi pada Masjid Baitur Roja' Jember dengan PSAK 109?

Berdasarkan rumusan masalah yang ada, maka tujuan yang hendak dicapai dari penelitian ini yaitu untuk mengetahui kesesuaian penyusunan akuntansi Masjid Baitur Roja' Jember dengan PSAK 109.

Manfaat praktis antara lain : 1) Bagi pengelola masjid diharapkan dapat memberikan masukan yang bermanfaat agar lebih ditingkatkan kinerja para pengelola masjid dalam mengelola keuangan dengan menerapkan praktik akuntansi sesuai dengan PSAK 109. 2) Bagi peneiti diharapkan dapat memberikan gambaran akan bentuk pelaporan keuangan zakat, infaq, shadaqah yang sesuai dengan kebutuhan masjid sebagai entitas publik. 3) Bagi penelitian selanjutnya diharapkan dapat dijadikan perbandingan dan referensi untuk penelitian selanjutnya agar penelitian lebih baik lagi guna menambah wawasan.

Kata zakat semula bermakna at-thaharah (bersih), al-nama' (tumbuh, dan berkembang), al-barokah (keberkahan), dan as-shalah (kesalehan). Secara istilah zakat adalah suatu kewajiban seorang muslim untuk mengeluarkan sebagian hartanya yang tidak melebihi satu nishab, diberikan kepada mustahiq sesuai dengan syari'at (Andri, 2009). Zakat memiliki peran yang sangat penting dalam upaya penanggulangan kemiskinan. Berbeda dengan sumber keuangan konvensional, zakat tidak memiliki dampak balik apapun kecuali ridha dari Allah SWT. Pihak yang berhak atas zakat menurut Al-Qur'an surah At-Taubah ayat 60, mereka yang berhak atas zakat adalah sebagai berikut: 1) Orang-orang fakir, 2) Orangorang miskin, 3) Amil Zakat, 4) Para Muallaf, 5) Program pembebasan budak, 6) Orang-orang yang tengah dililit hutang, 7) Program pembangunan agama (fi sabilillah), dan 8) Orang-orang yang sedang dalam perjalanan (ibnu sabil)

Infaq berasal dari kata anfaqa yang berarti mengeluarkan hartanya untuk kepentingan sesuatu. Menurut Mu'is (2011) infaq adalah mengeluarkan sebagian hartanya atau penghasilan untuk suatu kepentingan yang telah diperintahkan oleh agama islam. Infaq tidak mengenal nishab seperti zakat. Infaq dikeluarkan oleh setiap orang muslim yang beriman, baik yang berpenghasilan tinggi maupun rendah.

Pengertian Shadaqah berasal dari akar kata shadaqa jama' dari shidqan yang berarti kejujuran, dan berkata benar. Pengertian Shadaqah sama halnya dengan pengertian infak, perbedaannya adalah infak hanya berkaitan dengan materiil sedangkan shadaqah adalah pemberian secara suka rela yang dilakukan oleh seseorang kepada orang lain, terutama kepada orang-orang miskin. Shadaqah bisa dilakukan pada setiap kesempatan dan tidak ada ketentuan baik jenis, jumlah maupun waktunya. (Mardani, 2012).

Masjid merupakan sebuah kata yang berasal dari bahasa arab yaitu sajada yasjudu sujudan yang artinya tempat sujud, dengan demikian masjid adalah bangunan yang digunakan umat muslim sebagai tempat peribadatan. Secara terminologis, masjid mengandung makna sebagai pusat dari segala kebajikan 
kepada Allah SWT. Di dalamnya terdapat dua bentuk kebajikan, yang pertama yakni kebajikan yang dikemas dalam bentuk ibadah khusus, yaitu shalat fardhu dan yang kedua kebajikan yang dikemas dalam bentuk amaliyah sehari-hari untuk dapat berkomunikasi dan bersilaturahmi dengan sesama jama'ah (Suherman, 2012).

Adapun fungsi penunjang masjid adalah sebagai pusat kesehatan dan pengobatan, pendidikan, pusat informasi masyarakat, tempat akad nikah, tempat kegiatan ekonomi dan tempat untuk mengatur negara dan strategi perang.

Pernyataan ini bertujuan untuk mengatur pengakuan, pengukuran, penyajian dan pengungkapan transaksi zakat, infaq dan shadaqah. Perlakuan akuntansi dalam pembahasan ini mengacu pada PSAK 109, sehingga ruang lingkup PSAK ini hanya untuk amil zakat yang menerima dan menyalurkan zakat, infaq dan shadaqah, organisasi pengelola zakat yang pembentukannya dimaksudkan untuk mengumpulkan dan menyalurkan zakat. Komponen laporan keuangan lembaga amil, terdiri dari : 1)Neraca (laporan posisi keuangan), 2) Laporan perubahan dana, 3) Laporan perubahan aset kelolaan, 4) Laporan arus kas; dan 5) Catatan atas laporan keuangan

\section{Kerangka Pemecahan Masalah}

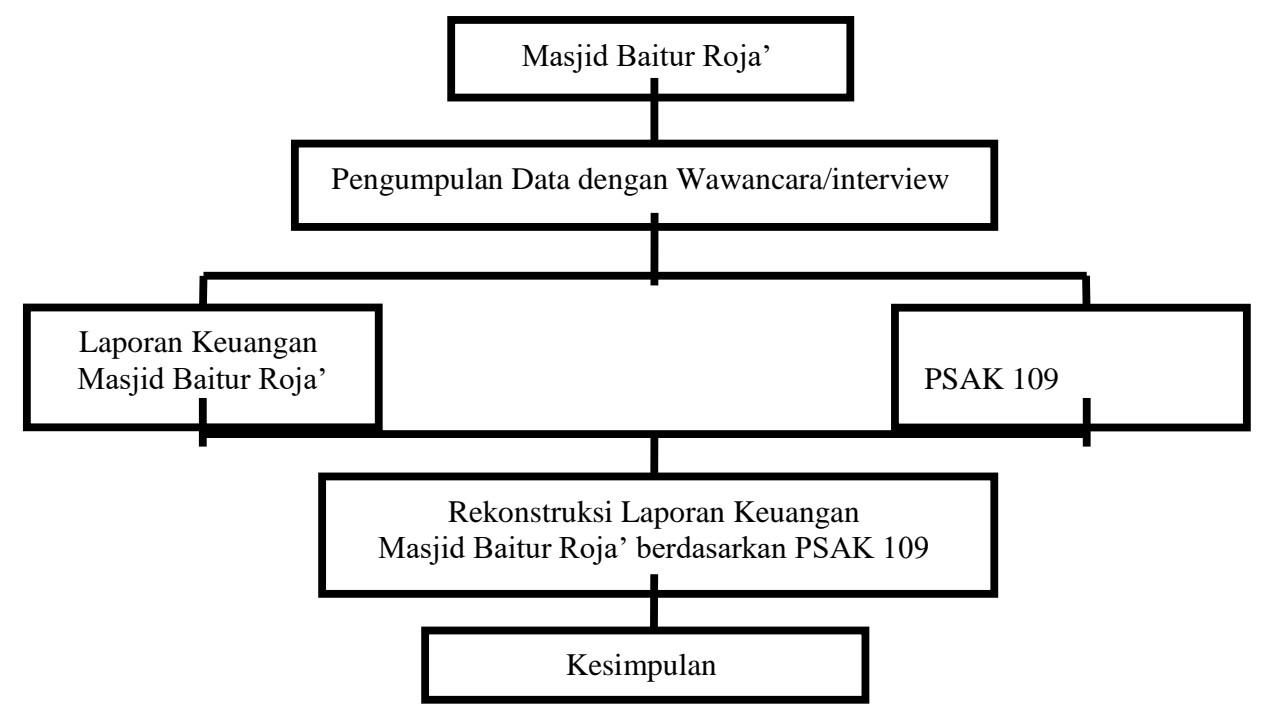

Gambar 1. Kerangka Pemecahan Masalah

\section{Metode}

Penelitian ini merupakan jenis penelitian deskriptif kualitatif. Jenis penelitian ini merupakan sebuah penelitian yang biasanya data yang digunakan berupa hasil wawacara, observasi dan dokumentasi. Penelitian kualitatif adalah penelitian yang menggunakan sistem tanya jawab untuk mendapatkan informasi tertentu dengan cara menggali informasi tersebut serta melihat kenyataan yang terjadi di lapangan sehingga mendapatkan informasi yang relevan dan andal (Afrizal, 2014).

Objek yang digunakan dalam penelitian ini yaitu di Masjid Baitur Roja' yang beralamat di Jalan Kenanga Nomor 90-92 Gebang Jember. Waktu penelitian ini dimulai pada bulan Oktober 2018 sampai dengan bulan Januari 2019.

Jenis data yang digunakan dalam penelitian ini menggunakan dua jenis sumber data yaitu 1) Data primer merupakan data yang diperoleh langsung dari hasil penelitian lapangan dan 2) Data sekunder merupakan data yang diperoleh melalui studi pustaka yang memiliki relevansi, serta dapat menunjang penelitian ini, yakni seperti data keuangan masjid, jurnal, literature, makalah, majalah, buku, koran, internet, dan sumber data lain yang dapat dijadikan sebagai data pelengkap.

Analisis data merupakan proses mengorganisasikan dan mengurutkan data ke dalam pola, kategori dan satuan uraian dasar sehingga dapat menemukan tema dan dapat dirumuskan hipotesis kerja seperti yang disarankan oleh data (Moleong, 2017). Berikut beberapa tahap-tahap dalam penelitian ini, sebagai berikut : 1) Pengumpulan data yang dilakukan yaitu dengan mengumpulkan data-data di Masjid Baitur Roja' Jember dengan observasi, wawancara dan dokumentasi, 2) Mengidentifikasi data laporan keuangan yang diterapkan di Masjid Baitur Roja' yang sesuai dengan PSAK 109, dan 3) Merekonstruksi data laporan 
keuangan yang telah diterapkan oleh Masjid Baitur Roja' dan disusun kembali dengan penerapan laporan keuangan masjid sesuai dengan PSAK 109.

Menyimpulkan hasil penelitian yang telah dilakukan di Masjid Baitur Roja' Jember.

\section{Hasil dan pembahasan}

Masjid Baitur Roja' Jember merupakan sebuah masjid wakaf yang berada di Jalan Kenanga nomor 90-92 Gebang Jember, yang mana lokasinya tidak jauh dari pusat kota Jember. Masjid ini berdiri sejak tahun 2005 yang dibangun diatas tanah wakaf seluas 1.200 meter persegi dengan bangunan sebesar kurang lebih 750 meter persegi, masjid baitur roja' saat ini diketuai oleh KH. Abdul Hamid Hasbullah.

Sumber pendanaan masjid diperoleh dari masyarakat yang bersifat sukarela dan tidak mengharapkan imbalan apapun. Dari penelitian tersebut sumber dana yang diperoleh lembaga masjid berasal dari sumbangan, kotak amal, zakat, dan infak/shadaqah. Selain mengumpulkan dana, Masjid Baitur Roja' Jember juga menyalurkan dana yang telah terkumpul tersebut untuk kepentingan organisasi maupun sebagai bentuk kegiatan sosial kemasyarakatan. Karena pengelola atau pengurus masjid yang biasa disebut takmir masjid menggunakan dana umat sesuai dengan ketentuan dalam ajaran islam.

Laporan keuangan lembaga masjid umumnya hanya dalam bentuk pencatatan penerimaan dan pengeluaran kas. Seharusnya laporan keuangan yang dikelola amil terdiri dari laporan posisi keuangan, laporan perubahan dana, laporan aset kelolaan, laporan arus kas dan catatan atas laporan keuangan. Berikut merupakan penyajian laporan keuangan sesuai dengan Pernyataan Standar Akuntansi Keuangan (PSAK) Nomor 109 pada lembaga masjid baitur roja' :

Tabel 1. Laporan Keuangan Masjid Baitur Roja' Jember

\begin{tabular}{llll}
\hline Bulan & Pemasukan & Pengeluaran & Saldo \\
\hline Saldo awal tahun 2018 & & & 132.760 .000 \\
Januari & 7.416 .000 & 4.597 .000 & 135.579 .000 \\
Februari & 6.078 .000 & 9.820 .000 & 131.837 .000 \\
Maret & 8.136 .000 & 11.276 .000 & 128.697 .000 \\
April & 6.027 .000 & 7.395 .000 & 127.329 .000 \\
Mei & 7.358 .000 & 10.852 .000 & 123.855 .000 \\
Juni & 19.226 .000 & 18.506 .000 & 124.555 .000 \\
Juli & 7.591 .000 & 3.348 .000 & 128.798 .000 \\
Agustus & 12.129 .000 & 9.732 .000 & 131.195 .000 \\
September & 5.937 .000 & 4.061 .000 & 133.071 .000 \\
Oktober & 6.850 .000 & 3.017 .000 & 136.904 .000 \\
November & 7.427 .000 & 13.417 .000 & 130.915 .000 \\
Desember & 7.267 .000 & 4.010 .000 & 134.172 .000 \\
Saldo akhir tahun 2018 & & & 134.172 .000 \\
\hline
\end{tabular}

Sumber : Masjid Baitur Roja' Jember

Tabel 2. Laporan Posisi Keuangan

\begin{tabular}{|c|c|c|c|}
\hline Keterangan & Rupiah & Keterangan & Rupiah \\
\hline ASET & & Kewajiban & \\
\hline Asset Lancar & & Kewajiban jangka pendek & \\
\hline Kas dan Setara Kas & 134.172 .000 & Biaya yang masih harus dibayar & \\
\hline & & Kewajiban jangka panjang & \\
\hline Jumlah Aset Lancar & 134.172 .000 & $\begin{array}{l}\text { Imbalan kerja jangka panjang } \\
\text { Jumlah Kewajiban }\end{array}$ & \\
\hline Aset tetap & & Saldo Dana & \\
\hline Tanah & 3.000 .000 .000 & Zakat & 3.225 .000 \\
\hline Bangunan & 1.500 .000 .000 & Infak/shadaqah & 161.672 .416 \\
\hline Akumulasi Penyusutan & $(125.000 .000)$ & Wakaf & 4.375 .000 .000 \\
\hline Peralatan & 66.105 .000 & Dana Amil & \\
\hline Akumulasi Penyusutan & $(35.379 .584)$ & & \\
\hline Jumlah Aset Tetap & 4.405 .725 .416 & Jumlah dana & 4.539.897.416 \\
\hline
\end{tabular}




\begin{tabular}{|c|c|c|c|}
\hline Jumlah aset & 4.539.897.416 & Jumlah Kewajiban dan Saldo Dana & 4.539.897.416 \\
\hline
\end{tabular}

Tabel 3. Laporan Perubahan Dana

\begin{tabular}{lc}
\hline Keterangan & (dalam) Rupiah \\
\hline DANA ZAKAT & \\
Penerimaan & \\
Penerimaan dari muzakki & \\
$\quad$ Muzakki entitas & \\
$\quad$ Muzakki individual & 56.805 .000 \\
Hasil Penempatan & 56.805 .000 \\
Jumlah penerimaan dana zakat & \\
Penyaluran & \\
Fakir-Miskin & $(53.580 .000)$ \\
Gharim & \\
Muallaf & \\
Sabilillah & \\
Jumlah penyaluran dana zakat & $(53.580 .000)$ \\
Surplus (defisit) & 3.225 .000 \\
DANA INFAK/SHADAQAH & \\
Penerimaan & \\
Infak/shadaqah tidak terikat mutlaqah & \\
Hasil pengelolaan & \\
Jumlah penerimaan dana infak/Shadaqah & 297.083 .000 \\
Penyaluran & \\
Honor amil & 297.083 .000 \\
Kegiatan kajian rutinan & \\
Penyusutan peralatan & \\
Operasional lembaga & \\
Jumlah penyaluran dana infak/shadaqah & $(3.600 .000)$ \\
Surplus (defisit) & $(35.379 .584)$ \\
& $(58.844 .000)$ \\
& $(135.410 .584)$ \\
& 161.672 .416 \\
\hline
\end{tabular}

Tabel 4. Laporan Perubahan Aset Kelolaan

\begin{tabular}{lllllll}
\hline & Saldo awal & $\begin{array}{l}\text { Penamb } \\
\text { ahan }\end{array}$ & $\begin{array}{l}\text { Penguran } \\
\text { gan }\end{array}$ & $\begin{array}{l}\text { Penyi } \\
\text { sihan }\end{array}$ & $\begin{array}{l}\text { Akumulasi } \\
\text { Penyusutan }\end{array}$ & $\begin{array}{l}\text { Saldo } \\
\text { Akhir }\end{array}$ \\
\hline $\begin{array}{l}\text { Dana infak/shadaqah- } \\
\text { aset kelolaan lancar }\end{array}$ & & & & & & \\
\\
$\begin{array}{l}\text { Dana infak/shadaqah- } \\
\text { aset kelolaan tidak lancar }\end{array}$ & $\mathrm{xxx}$ & $\mathrm{xxx}$ & $(\mathrm{xxx})$ & $(\mathrm{xxx})$ & - & $\mathrm{xxx}$ \\
\hline & & $\mathrm{xxx}$ & $(\mathrm{xxx})$ & - & $(\mathrm{xxx})$ & $\mathrm{xxx}$ \\
\hline
\end{tabular}

Tabel 5. Laporan Arus Kas

\begin{tabular}{ll}
\hline Saldo awal & \\
\hline Kas dan setara kas & 132.760 .000 \\
& \\
Arus kas masuk dari aktivitas operasi & 86.273 .000 \\
Infaq sholat jum'at & 7.025 .000 \\
Infaq sholat Idul Fitri & 4.290 .000 \\
Infaq Idul Adha & 630.000 \\
Infaq Akad Nikah & \\
\hline
\end{tabular}




\begin{tabular}{ll}
\hline Zakat maal & 3.225 .000 \\
Total arus kas masuk dari aktivitas operasi & 101.443 .000 \\
& \\
Arus kas keluar dari aktivitas operasional & \\
Biaya kebersihan & 1.040 .000 \\
Biaya keamanan & 840.000 \\
Biaya insentif masjid & 4.900 .000 \\
Biaya insentif khotib dan bilal & 8.840 .000 \\
Biaya honor amil & 3.600 .000 \\
Biaya pemeliharaan masjid & 25.448 .000 \\
Biaya insentif ustadz & 6.185 .000 \\
Biaya perbaikan masjid & 17.437 .000 \\
Biaya PLN,Telepon,PDAM & 6.638 .000 \\
Biaya Konsumsi & 7.441 .000 \\
Biaya kegiatan keagamaan & 17.662 .000 \\
Total arus kas keluar dari aktivitas operasional & 100.031 .000 \\
Saldo Kas Akhir Tahun & 134.172 .000 \\
\hline
\end{tabular}

Sumber : data diolah

a. Catatan Atas Laporan Keuangan

Masjid Baitur Roja' Jember merupakan sebuah masjid wakaf yang berada di Jalan Kenanga nomor 90-92 Gebang Jember, yang terletak di sebelah barat Kantor Kabupaten Jember. Masjid ini berdiri sejak tahun 2005 yang dibangun diatas tanah wakaf seluas 1.200 meter persegi dengan bangunan sebesar kurang lebih 750 meter persegi, saat ini diketuai oleh KH. Abdul Hamid Hasbullah. Masjid Baitur Roja'diwakafkan oleh Alm. Bapak H.A Akbar, yang merupakan keluarga besar Bapak Harun Wirio Wikoro dan Bapak Arpan Sumu Dikoro.

Visi dari Masjid Baitur Roja' Jember adalah terwujudnya masjid yang makmur sebagai sentra peribadatan dan pemberdayaan umat islam. sedangkan, misi dari Masjid Baitur Roja' Jember sebagai berikut : 1) Mengembangkan dakwah dan pembinaan umat islam melalui khutbah sholat jum'at dan kegiatan hari-hari besar Islam, 2) Memelihara kebersihan dan kesucian pada masjid, 3) Mengembangkan kesejahteraan dan pemberdayaan umat, melalui kegiatan amil zakat, infaq dan shadaqah, dan 4) Mengadakan perbaikan dan pemeliharaan bangunan masjid

Penyajian Laporan Keuangan pada Masjid Baitur Roja' Jember menggunakan Pernyataan Standar Akuntansi Keuangan (PSAK) Nomor 109 tentang pelaporan keuangan akuntansi zakat, infaq dan shadaqah. Pedoman penyajian laporan keuangan tersebut sesuai dengan Lembaga Masjid Baitur Roja' Jember yang bertujuan untuk menyajikan jumlah masing-masing kelompok saldo dana berdasarkan permintaan dari pihak muzakki yakni dana zakat, dana infaq/shadaqah, dana amil dan dana non halal. Periode pelaporan yang digunakan dalam penerapan laporan keuangan pada Lembaga Masjid Baitur Roja' Jember sesuai dengan PSAK 109 pada tahun 2018.

Laporan keuangan yang disusun pada lembaga Masjid Baitur Roja' Jember tidak membuat akun aset tetap. Hal ini dikarenakan tanah dan bangunan yang dimiliki oleh Masjid Baitur Roja' Jember merupakan tanah dan bangunan wakaf dari pihak perseorangan. Selain itu lembaga masjid juga tidak mencatat harga perolehan peralatan pada daftar aset tetap yang dimiliki. Untuk aset tetap seperti sertipikat tanah dan bangunan dipegang oleh Lembaga Masjid Baitur Roja' Jember.

Apabila melihat kondisi laporan keuangan yang disusun oleh Lembaga Masjid Baitur Roja' Jember, lembaga masjid sangat memerlukan laporan yang baik sesuai dengan standar pelaporan keuangan, sehingga dapat mencerminkan aktivitas operasional lembaga masjid yang nantinya dapat lebih mudah dipahami bagi pengguna laporan keuangan baik pihak donatur, amil ataupun pihak muzakki. Kendala yang dimiliki lembaga masjid yaitu belum adanya sumber daya manusia yang ahli dalam penyusunan laporan keuangan sesuai dengan standar akuntansi.

Selanjutnya jika penerapan PSAK 109 dilakukan oleh Masjid Baitur Roja' Jember maka lembaga masjid sebaiknya mencari sumber daya manusia yang berkualitas agar dapat memberikan pelatihan pada pengelola lembaga masjid terutama bendahara masjid agar mampu untuk menyajikan laporan keuangan sesuai dengan PSAK No.109 dan untuk meningkatkan transparansi keuangan lembaga masjid sebaiknya pengelola masjid mempublikasikan laporan keuangan melalui media sosial demi terjaganya akuntabilitas dana zakat, infaq dan shadaqah serta menjaga kepercayaan dari pihak donatur ataupun pihak muzakki. 


\section{Simpulan dan saran}

Berdasarkan hasil penelitian yang telah dilakukan oleh peneliti pada Lembaga Masjid Baitur Roja' Jember maka dapat diambil kesimpulan bahwa lembaga masjid masih belum menerapkan penyusunan pelaporan keuangan sesuai dengan Pernyataan Standar Akuntansi Keuangan (PSAK) Nomor 109, yaitu laporan posisi keuangan, laporan perubahan dana, laporan aset kelolaan, laporan arus kas dan catatan atas laporan keuangan. Laporan keuangan pada lembaga masjid hanya dalam bentuk penerimaan dan pengeluaran kas yang diperolah dari zakat, infaq dan shadaqah dan semua dana yang masuk pada Lembaga Masjid Baitur Roja' Jember belum dipisahkan berdasarkan golongan dana zakat, infaq dan shadaqah. Hal tersebut dikarenakan belum adanya sumber daya manusia yang ahli dalam penyusunan laporan keuangan sesuai dengan standar akuntansi.

Adapun saran peneliti yang mungkin dapat bermanfaat bagi lembaga masjid adalah peneliti menyarankan agar menyusun laporan keuangan sesuai dengan PSAK No.109, sehingga dapat menghasilkan laporan keuangan yang relevan dan andal serta dapat dipertanggungjawabkan kepada pengguna laporan keuangan yaitu masyarakat, amil dan pihak muzakki.

\section{Daftar Rujukan}

Al-Qur'an dan Terjemahnya. 2013. Pustaka Al-Mubin. Jakarta.

Ikatan Akuntan Indonesia. 2011. Pernyataan Standar Akuntansi Keuangan Nomor 109 tentang Akuntansi Zakat. Jakarta.

Lexy, Moleong. 2017. Metodologi Penelitian Kualitatif. PT. Remaja Rosdakarya. Bandung.

Mardani. 2012. Fiqih Ekonomi Syariah. Prenadamedia Group. Jakarta.

Mu'is, Fahrur. 2011. Zakat A-Z Panduan Mudah, Lengkap dan Praktis tentang Zakat. Tinta Medina. Solo.

Pratama, M.A. 2018. Analisis Penerapan Prinsip Akuntansi terhadap Akuntabilitas Laporan Keuangan Masjid (Studi Kasus 5 Masjid di Medan) (Doctoral Dissertation, Universitas Islam Negeri Sumatera Utara).

Republika.co.id. 2018. Potensi Zakat Solusi Perbaikan Ekonomi Indonesia. https://www.republika.co.id/berita/dunia-islam/wakaf/18/09/21/pfe1j4313-potensi-zakatsolusi-perbaikan-ekonomi-indonesia. (21 September 2018). 